\title{
Eficácia e seletividade de herbicidas em cultivares de feijão-caupi ${ }^{1}$
}

\author{
Effectiveness and selectivity of herbicides in cowpea cultivars
}

\begin{abstract}
Hélida Campos de Mesquita ${ }^{2}$; Francisco Cláudio Lopes de Freitas ${ }^{3}$; Francisco Rodrigues Freire Filho ${ }^{4}$; Márcio Gledson Oliveira da Silva ${ }^{5}$ Jorge Luiz Xavier Lins Cunha ${ }^{6}$; Ana Paula Medeiros dos Santos Rodrigues ${ }^{7}$
\end{abstract}

Resumo - Apesar da extensa área cultivada no Brasil e da crescente demanda sobre informações acerca do controle de plantas daninhas, poucos trabalhos são encontrados na literatura relatando a eficácia e a seletividade de herbicidas para a cultura do feijão-caupi (Vigna unguiculata). Diante disso, conduziu-se este trabalho com o objetivo avaliar a seletividade e eficácia de herbicidas para cultivares de feijão-caupi. Utilizou-se o delineamento experimental de blocos casualizados, em esquema fatorial 2 x 13, com dois cultivares (BRS Xiquexique e BRS Guariba) e 13 estratégias de manejo de plantas daninhas (1: S-metolachlor, 2: metribuzin + fluazifop, 3: imazamox + fluazifop, 4: bentazon + fluazifop, 5: imazamox + bentazon + fluazifop, 6: imazetapyr + fluazifop, 7 : fomesafen + fluazifop, 8: lactofen + fluazifop, 9: chlorimuron + fluazifop, 10: chlorimuron + lactofen + fluazifop, 11: capina + fluazifop, 12: testemunha capinada e 13: testemunha sem capina). Verificou-se que não há diferença de seletividade dos herbicidas avaliados para os cultivares BRS Guariba e BRS Xiquexique; os herbicidas 1, 3, 4, 5, e 6 são seletivos para a cultura do feijão-caupi; as misturas 7 e 8 causaram severa intoxicação, prolongamento do ciclo e redução na produtividade do feijão-caupi; Os herbicidas 2, 9 e 10 não são seletivos para o feijão-caupi; as misturas de herbicidas 5 e 6 foram eficazes no controle das espécies de plantas daninhas presentes na área com produtividade equivalente à testemunha capinada; a eficácia de herbicidas ou misturas de herbicidas para o controle de plantas daninhas depende da comunidade infestante.

Palavras-chaves: controle químico; plantas daninhas; Vigna unguiculata (L.) Walp

Abstract - Despite the extensive cultivated area in Brazil and the growing demand for information about weed control, few studies are found in literature reporting the efficacy and selectivity of herbicides for cowpea (Vigna unguiculata). View of this, this work was developed in order to evaluate the selectivity and efficacy of herbicides for cultivars of cowpea. The experiment was conducted in a randomized block design in factorial scheme $2 \times 13$, with two cowpea cultivars (BRS Xiquexique and BRS Guariba) and 13 strategies for weed management (1: S-metolachlor, 2: metribuzin + fluazifop, 3: imazamox + fluazifop, 4: bentazon + fluazifop, 5: imazamox + bentazon

\footnotetext{
${ }^{1}$ Recebido para publicação em 29/10/2016 e aceito em 24/11/2016.

${ }^{2}$ Professora do Instituto Federal de Educação, Ciência e Tecnologia do Rio Grande do Norte (IFRN). Apodi, RN, Brasil. E-mail: <helidamesquita.ifrn@gmail.com>.

${ }^{3}$ Professor da Universidade Federal de Viçosa (UFV), Viçosa-MG, Brasil. E-mail: <fclaudiof@yahoo.com.br>.

${ }^{4}$ Pesquisador da Empresa Brasileira de Pesquisa Agropecuária (Embrapa Meio-Norte). Teresina, PI, Brasil. E-mail: <francisco.freire-filho@embrapa.br>.

${ }^{5}$ Consultor da Syngenta. Aracati, CE. E-mail: <m_gledson@yahoo.com.br>.

${ }^{6}$ Professor da Universidade Federal de Alagoas (UFAL). Maceió, AL, Brasil. E-mail: <cunhajlx@ gmail.com>.

${ }^{7}$ Doutoranda em Fitotecnia na Universidade Federal Rural do Semi-Árido (UFERSA). Mossoró, RN, Brasil. E-mail: <anapaulamsr@hotmail.com>.
} 
+ fluazifop, 6: imazetapyr + fluazifop, 7: fomesafen + fluazifop, 8: lactofen + fluazifop, 9: chlorimuron + fluazifop, 10: chlorimuron + lactofen + fluazifop, 11: fluazifop + capina, 12: weeded control and 13: control without weeding). It was verified that there is no difference in the selectivity of the evaluated herbicides for the cultivars BRS Guariba and BRS Xiquexique. The herbicides 1; $3 ; 4 ; 5$ and 6 are selective for the cultivation of cowpea; The mixtures of herbicides 7 and 8 caused severe intoxication, prolonging the cycle and reduce the productivity of cowpea; Herbicides 2; 9; 10 are not selective for the cowpea; The mixtures of herbicides 5 and 6 were effective in the control of weed species present in the area with yield equivalent to the hand weeded; The effectiveness of herbicides or mixtures of herbicides for weed control depends on the weed community.

Keywords: chemical control; weeds; Vigna unguiculata (L.) Walp.

\section{Introdução}

A cultura do feijão-caupi (Vigna unguiculata (L.) Walp.) está entre as mais importantes espécies destinadas à alimentação humana. No ano de 2009 a área cultivada no Brasil foi de 1.543.373 ha, com destaque para as regiões Nordeste (1.368.113 ha), Norte (51.387 ha) e Centro-oeste (123.873 ha) (Freire Filho et al., 2011).

Dentre os diversos fatores que afetam a cultura do feijão-caupi, merece destaque a interferência exercida pelas plantas daninhas, pois competem por luz, nutrientes e água, o que se reflete diretamente na redução quantitativa e qualitativa da produção, além de aumentar os custos operacionais de colheita, secagem e beneficiamento dos grãos (Freitas et al., 2009b), sendo o seu controle considerado um dos principais componentes nos custos de produção (Fontes et al., 2010). Quando não controladas, as plantas daninhas podem reduzir o rendimento de grãos em até 90\% (Freitas et al., 2009a).

A estratégia de controle de plantas daninhas mais utilizada no feijão-caupi é a capina manual, por se tratar de uma cultura explorada principalmente no sistema de agricultura familiar (Freire Filho et al., 2011). Entretanto, em áreas extensas, o alto custo da mão-de-obra e a dificuldade de encontrar operários em quantidade suficiente, fazem com que este método seja apenas complementar aos demais (Freitas et al., 2009b).

O controle de plantas daninhas por meio da aplicação de herbicidas vem sendo amplamente empregado em diversas culturas anuais. Todavia, para a cultura do feijão-caupi a utilização desse método é limitada devido à escassez de trabalhos envolvendo a seletividade de herbicidas nesta cultura e à falta de agrotóxicos registrados junto ao Ministério da Agricultura Pecuária e Abastecimento, o que impede a recomendação e o uso de tais produtos no campo (Silva et al., 2009). A maioria das informações sobre a utilização de herbicidas está relacionada à cultura do feijão-comum (Phaseolus vulgaris L.) ou da soja (Glycine max (L.) Merr.). No entanto, a seletividade dos herbicidas pode variar de uma espécie para outra e entre cultivares dentro da mesma espécie, o que sugere o estudo da seletividade dos herbicidas para cada variedade cultivada.

Poucos trabalhos foram realizados avaliando a utilização de herbicidas para a cultura do feijão-caupi, onde se destacaram os seguintes herbicidas com relação à seletividade: bentazon, fluazifop, imazethapyr, Smetolachlor, (Silva, 2012) imazamox + bentazon (Silva, 2012; Linhares et al., 2013), imazamox (Silva et al., 2003; Silva, 2012), fenoxaprop (Silva et al., 2003), oxadiazon (Fontes et al., 2010), trifluralin (Freitas et al., 2010). Severa intoxicação com redução na produtividade foi verificada no feijão-caupi quando submetido à aplicação do herbicida fomesafen (Linhares et al., 2013), enquanto que para o lactofen, Silva (2012), constatou elevado nível de toxidez com posterior recuperação, sem perda na produtividade.

Diante da importância da cultura do feijão-caupi e da necessidade de desenvolver métodos de controle de plantas daninhas mais 
eficientes, o presente trabalho objetivou avaliar a seletividade e eficácia de herbicidas aplicados em pré e pós-emergência em dois cultivares de feijão-caupi.

\section{Material e Métodos}

O experimento foi conduzido no período de março a agosto de 2010. Utilizou-se o delineamento experimental de blocos casualizados em esquema fatorial 2 × 13, com quatro repetições, sendo duas cultivares de feijão-caupi (BRS Xiquexique e BRS Guariba) e 13 estratégias de manejo de plantas daninhas, conforme a Tabela 1.

Cada parcela experimental foi constituída de quatro fileiras de plantas de $5 \mathrm{~m}$ de comprimento, espaçadas entre si de $0,6 \mathrm{~m}$. A área útil de cada parcela foi composta pelas duas fileiras centrais descartando-se $0,50 \mathrm{~cm}$ em cada uma das extremidades.

Tabela 1. Relação dos tratamentos avaliados visando ao controle de plantas daninhas na cultura do feijão-caupi. Mossoró (RN), 2010.

\begin{tabular}{|c|c|}
\hline Tratamentos & Dose (g i.a. ha $\left.{ }^{-1}\right)$ \\
\hline S-metholachor ${ }^{1}$ & 1200 \\
\hline Metribuzin $^{1}$ & 400 \\
\hline Imazamox $^{2}+$ fluazifop-p-butil ${ }^{3}$ & $50+90$ \\
\hline Bentazon $^{2}+$ fluazifop-p-butil ${ }^{3}$ & $720+90$ \\
\hline Imazamox $^{2}+$ bentazon $^{2}+$ fluazifop-p-butil ${ }^{3}$ & $30+480+90$ \\
\hline Imazethapir $^{2}+$ fluazifop-p-butil ${ }^{3}$ & $100+90$ \\
\hline Fomesafen $^{2}+$ fluazifop-p-butil ${ }^{3}$ & $225+90$ \\
\hline Lactofen $^{2}+$ fluazifop-p-butil ${ }^{3}$ & $168+90$ \\
\hline Chlorimuron-ethyl $1^{2}+$ fluazifop-p-butil ${ }^{3}$ & $15+90$ \\
\hline Chlorimuron-ethyl $^{2}+$ lactofen $^{2}+$ fluazifop-p-butil ${ }^{3}$ & $7,5+62,5+90$ \\
\hline Capina + fluazifop-p-butil ${ }^{3}$ & 90 \\
\hline Testemunha capinada & - \\
\hline Testemunha sem capina & - \\
\hline
\end{tabular}

${ }^{1 /}$ Aplicação 1 dia após o plantio (DAP); ${ }^{2 /}$ Aplicação aos 14 DAP; ${ }^{3 /}$ Aplicação aos 19 DAP.

O preparo do solo foi realizado com uma aração seguida de duas gradagens. A adubação de plantio realizada com base na análise química do solo e na recomendação de Andrade Júnior (2013), utilizando-se $200 \mathrm{~kg} \mathrm{ha}^{-1}$ da formulação N-P-K 06-24-12. A semeadura foi realizada manualmente, com dez sementes por metro linear de fileira, no dia 21 de maio de 2010. O experimento foi conduzido sob irrigação por aspersão, com aplicação de água duas vezes por semana.

A aplicação dos herbicidas em préemergência (S-metholachor e metribuzin) foi efetuada um dia após o plantio (DAP), enquanto que a aplicação dos herbicidas em pósemergência foi efetuada em duas fases, sendo a primeira aos 14 DAP para os seguintes produtos (bentazon, imazamox, imazamox + bentazon, imazetapyr, fomesafen, lactofen, chlorimuron e chlorimuron + lactofen), quando a cultura estava com a segunda folha trifoliolada completamente expandida, já o herbicida fluazifop foi aplicado aos 19 DAP, de modo à evitar a possível incompatibilidade da mistura deste produto com herbicidas de outros mecanismos de ação. A aplicação foi realizada utilizando-se um pulverizador costal, equipado com barra com dois bicos XR 11002, espaçados de $40 \mathrm{~cm}$, mantidos à altura de $50 \mathrm{~cm}$ do alvo, à pressão de $250 \mathrm{kPa}$, com volume de calda de $200 \mathrm{~L} \mathrm{ha}^{-1}$. Durante a aplicação, as parcelas vizinhas foram protegidas lateralmente com placas de polietileno para evitar deriva. A testemunha capinada foi mantida no limpo durante todo ciclo por meio de capinas manuais.

A seletividade dos herbicidas para a cultura foi realizada por meio de avaliações visuais de intoxicação aos 7, 14 e 28 dias após a aplicação (DAA), utilizando-se a escala de 1 a 4, em que 1 representa ausência de intoxicação; 2, intoxicação leve; 3 , intoxicação moderada; e 4, intoxicação severa. Vale ressaltar que os 
tratamentos com os herbicidas aplicados em pré-emergência foram avaliados em datas diferentes dos aplicados em pós-emergência, sendo para estes, considerado a data dos produtos aplicados aos 14 dias após o plantio, e não o fluazifop, aplicado aos 19 dias após o plantio.

A eficácia dos herbicidas no controle de plantas daninhas foi determinada por meio de avaliações visuais aos 28 e 42 DAP, atribuindose notas de 0 a 100, em que, 0 foi ausência de controle e 100, controle total das plantas daninhas, por espécie, em relação à testemunha sem capinas. Aos 35 DAP foram realizadas avaliações de massa seca das plantas daninhas, por meio de uma amostragem em quadrado com $0,50 \mathrm{~m}$ de lado $\left(0,25 \mathrm{~m}^{2}\right)$ por parcela. As plantas foram colhidas ao nível do solo, separadas por espécie, contadas e levadas à estufa com circulação forçada de ar à temperatura de $65^{\circ} \mathrm{C}$, até massa constante, para determinação da massa seca.

Por ocasião da colheita, para a cultura do feijão-caupi, foram avaliados: o número de vagens por planta, número de grãos por vagem, obtidos mediante a contagem em 10 plantas na área útil da parcela; peso de 100 grãos e a produtividade de grãos, com unidade corrigida para $14 \%$, expressa em $\mathrm{kg} \mathrm{ha}^{-1}$.

Os dados obtidos foram submetidos à análise de variância pelo teste $\mathrm{F}$ e, em caso de significância, os dados foram comparados pelo teste de Duncan, a 5\% de probabilidade. Os desdobramentos das interações foram realizados independentemente da significância da interação entre fatores, variedades e estratégias de manejo.

\section{Resultados e Discussão}

Não se verificou diferença no nível de intoxicação entre os herbicidas avaliados para as variedades BRS Xiquexique e BRS Guariba, nem interação entre os fatores variedade $\mathrm{e}$ herbicidas sobre intoxicação das plantas de feijão-caupi, havendo somente diferença entre os herbicidas avaliados, aos 7, 14 e 30 dias após a aplicação (Tabela 2).

Tabela 2. Intoxicação de plantas de feijão-caupi em diferentes avaliações realizadas após a aplicação dos tratamentos contendo herbicidas. Mossoró (RN), 2010.

\begin{tabular}{|c|c|c|c|c|c|}
\hline \multirow{2}{*}{ Tratamentos } & \multicolumn{3}{|c|}{ Intoxicação } & \multirow{2}{*}{ Floração (DAP) } & \multirow{2}{*}{ Colheita (DAP) } \\
\hline & $7 \mathrm{DAA}$ & $14 \mathrm{DAA}$ & $30 \mathrm{DAA}$ & & \\
\hline S-metholachor ${ }^{1}$ & $1,7 \mathrm{f}$ & $1,4 \mathrm{de}$ & $1,0 \mathrm{~d}$ & $40,1 \mathrm{c}$ & $65,5 \mathrm{c}$ \\
\hline Metribuzin ${ }^{1}$ & $4,0 \mathrm{a}$ & $4,0 \mathrm{a}$ & $4,0 \mathrm{a}$ & - & - \\
\hline Imazamox $^{2}+$ fluazifop $^{3}$ & $2,0 \mathrm{~d}$ & $1,7 \mathrm{c}$ & $1,0 \mathrm{~d}$ & $40,6 \mathrm{c}$ & $65,6 \mathrm{c}$ \\
\hline Bentazon $^{2}+$ fluazifop $^{3}$ & $1,9 \mathrm{de}$ & $1,4 \mathrm{de}$ & $1,0 \mathrm{~d}$ & $41,1 \mathrm{c}$ & $67,1 \mathrm{c}$ \\
\hline Imazamox + bentazon + fluazifop ${ }^{3}$ & $1,9 \mathrm{de}$ & $1,6 \mathrm{~cd}$ & $1,1 \mathrm{~d}$ & $40,5 \mathrm{c}$ & $66,4 \mathrm{c}$ \\
\hline Imazethapyr $^{2}+$ fluazifop $^{3}$ & 1,8 ef & $1,3 \mathrm{e}$ & $1,0 \mathrm{~d}$ & $40,8 \mathrm{c}$ & $65,8 \mathrm{c}$ \\
\hline Fomesafen $^{2}+$ fluazifop $^{3}$ & $3,7 \mathrm{c}$ & $2,8 \mathrm{~b}$ & $1,5 \mathrm{c}$ & 54,5 a & 80,9 a \\
\hline Lactofen $^{2}+$ fluazifop $^{3}$ & $3,6 \mathrm{c}$ & $2,8 \mathrm{~b}$ & $1,8 \mathrm{~b}$ & $48,6 \mathrm{~b}$ & $74,6 \mathrm{~b}$ \\
\hline Chlorimuron $^{2}+$ fluazifop $^{3}$ & $3,9 \mathrm{ab}$ & $4,0 \mathrm{a}$ & $4,0 \mathrm{a}$ & - & - \\
\hline Chlorimuron $^{2}+$ lactofen + fluazifop ${ }^{3}$ & $3,8 \mathrm{ab}$ & $4,0 \mathrm{a}$ & $4,0 \mathrm{a}$ & - & - \\
\hline Capina + fluazifop ${ }^{3}$ & $1,0 \mathrm{~g}$ & $1,0 \mathrm{f}$ & $1,0 \mathrm{~d}$ & $40,3 \mathrm{c}$ & $67,5 \mathrm{c}$ \\
\hline Testemunha capinada & $1,0 \mathrm{~g}$ & $1,0 \mathrm{f}$ & $1,0 \mathrm{~d}$ & $40,9 \mathrm{c}$ & $65,8 \mathrm{c}$ \\
\hline Testemunha sem capina & $1,0 \mathrm{~g}$ & $1,0 \mathrm{f}$ & $1,0 \mathrm{~d}$ & $39,8 \mathrm{c}$ & $65,0 \mathrm{c}$ \\
\hline
\end{tabular}

${ }^{1 /}$ Aplicação 1 DAP; ${ }^{2 /}$ Aplicação aos 14 DAP; ${ }^{3 /}$ Aplicação aos 19 DAP. * Nas colunas, médias seguidas de mesmas letras não diferiram estatisticamente pelo teste Duncan a 5\% de probabilidade.

Aos 7 DAA, maiores níveis de intoxicação da cultura foram causados pelos herbicidas metribuzin, chlorimuron + fluazifop $\mathrm{e}$ chlorimuron + lactofen + fluazifop, apresentando sintomas severos que levaram as plantas à morte (Tabela 2). Nesta mesma época de avaliação, os herbicidas fomesafen e lactofen também causaram sintomas de intoxicação severos no feijão-caupi, porém, com posterior recuperação das plantas que aos 14 e 30 DAA, sendo que aos 30 DAA as plantas se encontravam em fase de recuperação avançada, 
emitindo novas folhas, porém com visível retardamento no crescimento $\mathrm{e}$ desenvolvimento, atrasando o florescimento e a colheita em 15 e 9 dias em relação à testemunha sem herbicidas com capinas, para o fomesafen e lactofen, respectivamente. Os resultados obtidos nos demais tratamentos concordam com os observados por Silva et al. (2013) que constataram média de 44 dias para florescimento da cultivar BRS Guariba em Serra Talhada (PE). Já Andrade (2010), nas condições de Teresina (PI), encontrou amplitude variando entre 36 a 40 dias para o florescimento desta cultivar.

Freitas et al. (2010), avaliando a seletividade de herbicidas para a cultura do feijão-caupi, também verificaram que os herbicidas lactofen e fomesafen, causaram severa intoxicação nas plantas, com posterior recuperação e 13 dias de atraso no florescimento e na colheita para o tratamento submetido à aplicação do fomesafen. Também, Linhares et al. (2013) constataram severa intoxicação do fomesafen no feijão-caupi, acarretando atraso de 7 dias na floração e na colheita.

Para a cultura da soja, Correa e Alves (2009) verificaram que o herbicida lactofen em mistura com outros herbicidas causou apenas intoxicação leve, sendo que os sintomas se tornaram menos intensos após os 13 DAA. Enquanto que na cultura da mandioca Silva $e t$ al. (2011) constataram que a aplicação do fomesafen isolado ou em mistura com o fluazifop causou elevado índice intoxicação na cultura aos 7 DAA, com posterior redução dos sintomas aos 35 DAA, com emissão de novas folhas.

Os herbicidas bentazon + fluazifop, imazamox + fluazifop, imazamox + bentazon + fluazifop, imazetapyr + fluazifop e Smetholochlor causaram apenas sintomas leves de intoxicação na cultura aos 7 DAA, sendo que aos 30 DAA as plantas estavam totalmente recuperadas (Tabela 2), não exercendo influência sobre a época de floração e colheita das plantas. Freitas et al. (2010) e Silva (2012) verificaram seletividade dos herbicidas $\mathrm{S}$ - metholochlor, fluazifop, imazethapyr, imazamox, bentazon e imazamox + bentazon para o feijão-caupi.

No tratamento com capinas + fluazifop, não se verificou nenhum sinal visível de intoxicação na cultura, justificando assim sua utilização associada aos demais herbicidas. O fluazifop é um herbicida que atua na inibição da enzima Acetil-Co A carboxilase (ACC-ase) na biossíntese de ácidos graxos nos vegetais, sendo utilizado exclusivamente no controle de gramíneas, e seletivo para as dicotiledôneas. A seletividade ocorre devido as enzimas ACC-ase plastídicas nas plantas da família Poaceae apresentarem seus domínios funcionais em uma única cadeia polipeptídica, que são sensíveis ao herbicida, enquanto que as demais espécies têm seus domínios codificados por diferentes genes, uma forma insensível da enzima (Burke et al., 2006). Apesar de não se ter verificado diferença entre as cultivares avaliadas para os herbicidas em estudo neste trabalho, Harrison Jr. e Fery (1993), avaliando a tolerância de germoplasmas de feijão-caupi ao herbicida bentazon, encontraram tanto genótipos susceptíveis como altamente tolerantes, demonstrando a necessidade de estudos sobre seletividade dos herbicidas para as diferentes variedades.

As principais espécies de plantas daninhas que ocorreram na área experimental foram mussambê (Cleome affinis), bredo (Trianthema portulacastrum), caruru de espinho (Amaranthus spinosus), trapoeraba (Commelina bengalensis) e beldroega (Portulaca oleraceae). A incidência de gramíneas na área foi insignificante mesmo na testemunha sem capinas e sem herbicidas. Nos tratamentos com herbicidas este grupo de plantas foi controlado com a aplicação do graminicida fluazifop em mistura com os demais produtos.

Não se verificou efeito dos cultivares nem interação entre os fatores cultivar e estratégias de manejo para a variável controle das plantas daninhas. Entretanto, verificou-se efeito diferenciado das estratégias de manejo sobre o nível de controle sobre as diferentes 
espécies infestantes nas avaliações realizadas aos 28 e 42 DAP (Tabela 3).

O herbicida metribuzin e as misturas chlorimuron + fluazifop e chlorimuron + lactofen + fluazifop apresentaram eficiência no controle das espécies incidentes aos 28 DAE, com índices acima 80\% (Tabela 3), porém ocasionaram a morte da cultura (Tabela 2).
Resultados semelhantes foram observados na cultura da soja por Galon et al. (2007), onde verificaram que o chlorimuron e chlorimuron + lactofen exerceram controle de $49 \%$ e $100 \%$ sobre plantas de $P$. oleraceae, respectivamente, assim como controle de $88 \%$ e $100 \%$ sobre Amaranthus lividus L.

Tabela 3. Porcentagem de controle de plantas daninhas imposta pelos diferentes tratamentos utilizados na cultura do feijão-caupi. Mossoró (RN), 2010.

\begin{tabular}{|c|c|c|c|c|c|}
\hline \multirow{2}{*}{ Tratamentos } & C. afins & T. portulacastrum & A. spinosus & P. oleraceae & C. bengalensis \\
\hline & \multicolumn{5}{|c|}{$28 \mathrm{DAP}$} \\
\hline$\overline{\text { S-metholachor }}{ }^{1}$ & $39,0 \mathrm{c}$ & $89,4 a$ & $91,9 \mathrm{a}$ & $97,5 \mathrm{a}$ & $98,8 \mathrm{a}$ \\
\hline Metribuzin $^{1}$ & $74,4 \mathrm{~b}$ & 93,0 a & $98,5 \mathrm{a}$ & $100,0 \mathrm{a}$ & $98,8 \mathrm{a}$ \\
\hline Imazamox $^{2}+$ fluazifop $^{3}$ & $98,1 \mathrm{a}$ & $67,5 \mathrm{~b}$ & $98,1 \mathrm{a}$ & $83,1 \mathrm{c}$ & $92,5 \mathrm{ab}$ \\
\hline Bentazon $^{2}+$ fluazifop $^{3}$ & $98,8 \mathrm{a}$ & $89,4 \mathrm{a}$ & $41,3 \mathrm{~b}$ & 96,3 a & $94,4 \mathrm{ab}$ \\
\hline Imazamox + bentazon + fluazifop ${ }^{3}$ & $98,1 \mathrm{a}$ & 89,4 a & 99,4 a & $92,5 \mathrm{ab}$ & $97,5 \mathrm{ab}$ \\
\hline Imazethapyr $^{2}+$ fluazifop $^{3}$ & 97,5 a & $93,8 \mathrm{a}$ & $97,5 \mathrm{a}$ & $84,4 \mathrm{bc}$ & $91,3 \mathrm{ab}$ \\
\hline Fomesafen $^{2}+$ fluazifop $^{3}$ & $98,1 \mathrm{a}$ & $91,9 \mathrm{a}$ & $90,6 \mathrm{a}$ & $87,5 \mathrm{bc}$ & $79,1 \mathrm{c}$ \\
\hline Lactofen $^{2}+$ fluazifop $^{3}$ & $99,4 \mathrm{a}$ & $97,5 \mathrm{a}$ & 98,8 a & 96,9 a & $92,5 \mathrm{ab}$ \\
\hline Chlorimuron $^{2}+$ fluazifop $^{3}$ & $100,0 \mathrm{a}$ & 90,9 a & 98,8 a & $94,4 \mathrm{ab}$ & $90,6 \mathrm{~b}$ \\
\hline \multirow{2}{*}{ Chlorimuron $^{2}+$ lactofen + fluazifop ${ }^{3}$} & $100,0 \mathrm{a}$ & $95,0 \mathrm{a}$ & $95,6 \mathrm{a}$ & $90,6 \mathrm{~b}$ & $93,1 \mathrm{ab}$ \\
\hline & \multicolumn{5}{|c|}{$42 \mathrm{DAP}$} \\
\hline$\overline{\text { S-metholachor }}{ }^{1}$ & $7,8 \mathrm{c}$ & $90,4 \mathrm{a}$ & $87,9 \mathrm{a}$ & $86,9 \mathrm{a}$ & $94,4 \mathrm{a}$ \\
\hline Metribuzin $^{1}$ & $56,3 \mathrm{~b}$ & $71,0 \mathrm{~d}$ & 90,4 a & $97,5 \mathrm{a}$ & $80,6 \mathrm{c}$ \\
\hline Imazamox $^{2}+$ fluazifop $^{3}$ & $91,3 \mathrm{a}$ & $54,4 \mathrm{e}$ & $100,0 \mathrm{a}$ & $79,1 \mathrm{a}$ & $83,8 \mathrm{bc}$ \\
\hline Bentazon $^{2}+$ fluazifop $^{3}$ & $92,5 \mathrm{a}$ & $75,6 \mathrm{c}$ & $20,6 \mathrm{~b}$ & $90,4 \mathrm{a}$ & $91,9 \mathrm{ab}$ \\
\hline Imazamox + bentazon + fluazifop $^{3}$ & $91,3 \mathrm{a}$ & $70,0 \mathrm{~d}$ & $87,5 \mathrm{a}$ & 89,4 a & $92,5 \mathrm{a}$ \\
\hline Imazethapyr $^{2}+$ fluazifop $^{3}$ & $93,1 \mathrm{a}$ & $81,9 \mathrm{bc}$ & $93,1 \mathrm{a}$ & 86,9 a & $89,4 \mathrm{ab}$ \\
\hline Fomesafen $^{2}+$ fluazifop $^{3}$ & $93,8 \mathrm{a}$ & $78,8 \mathrm{bc}$ & $90,6 \mathrm{a}$ & $82,5 \mathrm{a}$ & $83,8 \mathrm{bc}$ \\
\hline Lactofen $^{2}+$ fluazifop $^{3}$ & $92,5 \mathrm{a}$ & $90,6 \mathrm{a}$ & 93,8 a & $92,5 \mathrm{a}$ & $88,1 \mathrm{abc}$ \\
\hline Chlorimuron $^{2}+$ fluazifop $^{3}$ & $95,0 \mathrm{a}$ & $80,0 \mathrm{bc}$ & 90,0 a & $86,3 \mathrm{a}$ & $88,8 \mathrm{abc}$ \\
\hline Chlorimuron $^{2}+$ lactofen + fluazifop ${ }^{3}$ & $95,0 \mathrm{a}$ & $87,5 \mathrm{ab}$ & $88,8 \mathrm{a}$ & $85,6 \mathrm{a}$ & $83,8 \mathrm{bc}$ \\
\hline
\end{tabular}

As misturas fomesafen + fluazifop e lactofen + fluazifop também exerceram controle acima de $80 \%$ sobre as espécies infestantes aos 28 e 42 DAP (Tabela 3), resultando em baixo acúmulo de massa seca aos 35 DAE (Tabela 4), porém causaram intoxicação na cultura e prolongamento no ciclo (Tabela 2). Machado et al. (2006) verificaram que o fomesafen em mistura com fluazifop aplicado na cultura do feijão-comum exerceu controle de espécies de plantas daninhas dicotiledôneas e monocotiledôneas, com exceção da tiririca (Cyperus rotundus).

O S-metholochlor controlou satisfatoriamente as espécies $T$. portulacastrum,
A. spinosus, $C$. bengalensis e $P$. oleraceae aos 14 DAA, porém, não demonstrou eficácia no controle do $C$. affinis (Tabela 3), que foi uma das espécies mais importantes neste trabalho, devido elevado índice de infestação e a características como rápida taxa de crescimento inicial. Segundo Silva (2012), essa espécie se torna uma importante competidora com a cultura quando presente em alta densidade e se faz o controle eficiente de outras espécies, como foi o caso das parcelas em que se utilizou o herbicida S-metholochlor, onde se verificou intenso acúmulo de massa seca, alcançando valores superiores à testemunha sem capinas (Tabela 4). 
Tabela 4. Massa seca de plantas daninhas e total $\left(\mathrm{g} \mathrm{m}^{-2}\right)$ em função da aplicação de diferentes tratamentos na cultura do feijão-caupi. Mossoró (RN), 2010.

\begin{tabular}{|c|c|c|c|c|c|c|}
\hline Tratamentos & C. affinis & T. portulacastrum & A. spinosus & P. oleraceae & C. bengalensis & Total \\
\hline S-metholachor ${ }^{1}$ & $66,3 \mathrm{a}$ & $0,8 \mathrm{e}$ & $0,4 \mathrm{~b}$ & $2,4 \mathrm{bc}$ & $0,8 \mathrm{c}$ & $72,0 \mathrm{a}$ \\
\hline Metribuzin $^{1}$ & $34,1 \mathrm{~b}$ & 10,4 de & $9,4 \mathrm{a}$ & $0,2 \mathrm{c}$ & $0,5 \mathrm{c}$ & $54,8 \mathrm{~b}$ \\
\hline Imazamox $^{2}+$ fluazifop $^{3}$ & $0,0 \mathrm{~d}$ & $20,8 \mathrm{a}$ & $0,0 \mathrm{~b}$ & $0,0 \mathrm{c}$ & $0,0 \mathrm{c}$ & $27,1 \mathrm{~cd}$ \\
\hline Bentazon $^{2}+$ fluazifop $^{3}$ & $0,0 \mathrm{~cd}$ & $14,6 \mathrm{ab}$ & $4,5 \mathrm{a}$ & $0,0 \mathrm{c}$ & $0,1 \mathrm{c}$ & $36,0 \mathrm{c}$ \\
\hline Imazamox + bentazon + fluazifop $^{3}$ & $0,0 \mathrm{~d}$ & $7,8 \mathrm{~cd}$ & $0,5 \mathrm{~b}$ & $6,9 \mathrm{a}$ & $3,2 \mathrm{~b}$ & $18,9 \mathrm{de}$ \\
\hline Imazethapyr $^{2}+$ fluazifop $^{3}$ & $0,1 \mathrm{~d}$ & $7,7 \mathrm{bc}$ & $0,0 \mathrm{~b}$ & $4,6 \mathrm{ab}$ & $0,6 \mathrm{c}$ & $23,5 \mathrm{de}$ \\
\hline Fomesafen $^{2}+$ fluazifop $^{3}$ & $0,0 \mathrm{~d}$ & $3,4 \mathrm{~cd}$ & $0,2 \mathrm{~b}$ & $0,6 \mathrm{bc}$ & $1,4 \mathrm{bc}$ & $16,6 \mathrm{e}$ \\
\hline Lactofen $^{2}+$ fluazifop $^{3}$ & $0,1 \mathrm{~d}$ & $0,5 \mathrm{de}$ & $0,0 \mathrm{~b}$ & $0,1 \mathrm{c}$ & $0,3 \mathrm{c}$ & $14,7 \mathrm{e}$ \\
\hline Chlorimuron $^{2}+$ fluazifop $^{3}$ & $0,2 \mathrm{~d}$ & 3,2 cde & $0,1 \mathrm{~b}$ & $2,8 \mathrm{abc}$ & $0,0 \mathrm{c}$ & $15,7 \mathrm{e}$ \\
\hline Chlorimuron $^{2}+$ lactofen + fluazifop $^{3}$ & $0,0 \mathrm{~cd}$ & $0,0 \mathrm{e}$ & $0,0 \mathrm{~b}$ & $0,3 \mathrm{bc}$ & $0,2 \mathrm{c}$ & $17,3 \mathrm{e}$ \\
\hline Capina + fluazifop ${ }^{3}$ & $0,0 \mathrm{~cd}$ & $0,0 \mathrm{e}$ & $0,0 \mathrm{~b}$ & $0,0 \mathrm{c}$ & $0,0 \mathrm{c}$ & $0,0 \mathrm{f}$ \\
\hline Testemunha capinada & $0,0 \mathrm{~cd}$ & $0,0 \mathrm{e}$ & $0,0 \mathrm{~b}$ & $0,0 \mathrm{c}$ & $0,0 \mathrm{c}$ & $0,0 \mathrm{f}$ \\
\hline Testemunha sem capina & $5,9 \mathrm{c}$ & $20,6 \mathrm{a}$ & $6,9 \mathrm{a}$ & $1,8 \mathrm{bc}$ & $5,5 \mathrm{a}$ & $52,0 \mathrm{~b}$ \\
\hline
\end{tabular}

Ao contrário do S-metholochlor, a mistura bentazon + fluazifop controlou eficientemente o $C$. affinis, assim como o $T$. portulacastrum, a $C$. bengalensis e a $P$. oleraceae, porém não controlou o $A$. spinosus (Tabela 3), resultando em acúmulo de massa seca desta espécie semelhante à testemunha sem controle (Tabela 4). Este resultado está de acordo com Machado et al. (2006), Freitas et al. (2009b) e Silva (2012), que relataram baixa eficácia do bentazon no controle do Amaranthus sp.

Dentre os herbicidas/misturas de herbicidas que apresentaram seletividade para o feijão-caupi, as misturas imazamox + bentazon + fluazifop e imazethapir + fluazifop foram as que exerceram melhor índice de controle das plantas infestantes (Tabela 3). A mistura de herbicidas com diferentes mecanismos de ação pode apresentar diversas vantagens como redução do risco da seleção de biótipos resistentes, controle de maior número de espécies de plantas daninhas e uso de doses menores de cada herbicida, podendo possibilitar o cultivo de espécies suscetíveis em sucessão. Segundo Machado et al. (2006), a redução da dose tem como consequência a redução da intoxicação na cultura e do período residual de herbicidas no solo, podendo possibilitar o cultivo de espécies suscetíveis em sucessão.

Para as variáveis número de vagens por planta, número de grãos por vagens $\mathrm{e}$ produtividade, verificou-se efeito significativo para os fatores variedades e herbicidas, bem como a interação entre os mesmos (Tabelas 5 e 6). Os maiores valores nestas variáveis foram constatados nos tratamentos com capinas, com capinas + aplicação de fluazifop e com as misturas imazamox + bentazon + fluazifop e imazethapir + fluazifop, que combinaram seletividade com bom índice de controle das plantas infestantes. $\mathrm{O}$ s-metholachlor $\mathrm{e}$ as misturas imazamox + fluazifop e bentazon + fluazifop, apesar de seletivos (Tabela 2), não apresentaram controle satisfatório das espécies C. affinis, T. portulacastrum e A. spinosus, respectivamente (Tabelas 3 e 4), resultando em perda na produtividade (Tabela 6). Todavia, em áreas sem infestação destas espécies ou outras que por ventura não exerçam boa eficácia, estes herbicidas podem apresentar boa eficácia. Segundo Marques et al. (2011), a comunidade infestante na cultura do feijão-caupi varia no decorrer dos ciclos produtivos em razão das alterações das culturas e das práticas de manejo.

A variável massa de cem grãos não foi influenciada pelos herbicidas/misturas de herbicidas utilizados, nem mesmo pelos que causaram sintomas mais severos de intoxicação, como o fomesafen + fluazifop e lactofen + fluazifop. Foram verificadas apenas diferenças estatísticas entre as variedades avaliadas, com maiores valores obtidos para a BRS Guariba (Tabela 6). O fato demostra que o peso de cem grãos é uma característica inerente da própria variedade, sem influência dos herbicidas. Esses 
resultados concordam com Linhares et al. (2013) que não constataram efeito do fomesafen sobre esta característica. Freitas et al. (2009a) também não verificaram variação na massa de sementes devido à competição de plantas daninhas, sendo essa característica inerente ao cultivar, não influenciada pelas condições de manejo.

Tabela 5. Número de vagens por planta (NVP) e número de grãos por vagem (NGV) de duas variedades de feijão-caupi submetidas a diferentes tratamentos visando ao controle de plantas daninhas. Mossoró (RN), 2010.

\begin{tabular}{|c|c|c|c|c|}
\hline \multirow{2}{*}{ Tratamentos } & \multicolumn{2}{|c|}{ NVP } & \multicolumn{2}{|c|}{ NGV } \\
\hline & BRS Xiquexique & BRS Guariba & BRS Xiquexique & BRS Guariba \\
\hline S-metholachor ${ }^{1}$ & $4,4 \mathrm{bcA}$ & $3,6 \mathrm{bB}$ & $6,8 \mathrm{cB}$ & $8,1 \mathrm{aA}$ \\
\hline Metribuzin ${ }^{1}$ & $0,0 \mathrm{fA}$ & $0,0 \mathrm{cA}$ & $0,0 \mathrm{dA}$ & $0,0 \mathrm{dA}$ \\
\hline Imazamox $^{2}+$ fluazifop $^{3}$ & $6,1 \mathrm{aA}$ & $3,4 \mathrm{bB}$ & $11,1 \mathrm{aA}$ & $8,5 \mathrm{aB}$ \\
\hline Bentazon $^{2}+$ fluazifop $^{3}$ & $3,2 \mathrm{deB}$ & $4,3 \mathrm{abA}$ & $9,2 \mathrm{bA}$ & $7,5 \mathrm{abB}$ \\
\hline Imazamox + bentazon + fluazifop ${ }^{3}$ & $5,3 \mathrm{abA}$ & $4,9 \mathrm{abA}$ & $9,4 \mathrm{bA}$ & $8,6 \mathrm{aA}$ \\
\hline Imazethapyr $^{2}+$ fluazifop $^{3}$ & $5,2 \mathrm{abA}$ & $4,5 \mathrm{abA}$ & $8,6 \mathrm{bA}$ & $8,7 \mathrm{aA}$ \\
\hline Fomesafen $^{2}+$ fluazifop $^{3}$ & $3,9 \mathrm{cdA}$ & $1,5 \mathrm{cB}$ & $6,5 \mathrm{cB}$ & $8,0 \mathrm{aA}$ \\
\hline Lactofen $^{2}+$ fluazifop $^{3}$ & $2,4 \mathrm{eB}$ & $3,1 \mathrm{bA}$ & $8,4 \mathrm{bA}$ & $6,9 \mathrm{bB}$ \\
\hline Chlorimuron $^{2}+$ fluazifop $^{3}$ & $0,0 \mathrm{fA}$ & $0,0 \mathrm{cA}$ & $0,0 \mathrm{dA}$ & $0,0 \mathrm{dA}$ \\
\hline Chlorimuron $^{2}+$ lactofen + fluazifop ${ }^{3}$ & $0,0 \mathrm{fA}$ & $0,0 \mathrm{cA}$ & $0,0 \mathrm{dA}$ & $0,0 \mathrm{dA}$ \\
\hline Capina + fluazifop ${ }^{3}$ & $4,8 \mathrm{bcA}$ & $4,4 \mathrm{abA}$ & $11,4 \mathrm{aA}$ & $8,6 \mathrm{aB}$ \\
\hline Testemunha capinada & $5,48 \mathrm{abA}$ & $5,6 \mathrm{aA}$ & $9,7 \mathrm{bA}$ & $8,6 \mathrm{aA}$ \\
\hline Testemunha sem capina & 3,2 de $\mathrm{A}$ & $4,1 \mathrm{abA}$ & $7,0 \mathrm{cA}$ & $5,3 \mathrm{cA}$ \\
\hline
\end{tabular}

${ }^{1 /}$ Aplicação 1 DAP; ${ }^{2 /}$ Aplicação aos 14 DAP; ${ }^{3 /}$ Aplicação aos 19 DAP. * Nas colunas, letras minúsculas comparam as médias das estratégias de controle dentro de cada variedade pelo teste de Duncan a 5\% de probabilidade e nas linhas, para cada característica avaliada, letras maiúsculas comparam as variedades dentro de cada estratégia de controle pelo teste $\mathrm{F}$ a $5 \%$ de probabilidade.

As misturas fomesafen + fluazifop e lactofen + fluazifop, diferentemente das anteriormente citadas, apresentaram eficácia no controle das plantas infestantes (Tabelas 3 e 4), mas a recuperação do crescimento vegetativo após a severa intoxicação nas plantas (Tabela 2) não foi suficiente para evitar queda no número de vagens por planta, no número de grãos por vagem e na produtividade da cultura do feijãocaupi. Esses resultados estão de acordo com Linhares et al. (2013) que verificaram redução nas respectivas variáveis na cultura do feijãocaupi devido à intoxicação causada pelo fomesafen.

Silva (2012) verificou que a mistura lactofen + fluazifop causou severa intoxicação na cultura do feijão-caupi, com posterior recuperação e produtividade superior ao tratamento mantido no limpo por meio de capinas e aos submetidos à aplicação de outros herbicidas com ausência de intoxicação, o que segundo a autora, se deve ao efeito da intoxicação causada pelo herbicida restringindo a taxa de crescimento, que nos tratamentos sem intoxicação foi elevada devido ao alto índice pluviométrico ocorrido no ciclo da cultura, promovendo intenso crescimento vegetativo, acarretando a competição intraespecífica e consequente queda na produtividade.

A produtividade obtida neste trabalho para os tratamentos com controle adequado das plantas infestantes e sem intoxicação na cultura é semelhante às encontradas em outros trabalhos como $1.494 \mathrm{~kg} \mathrm{ha}^{-1}$ (Rocha et al., 2007), 1.350 $\mathrm{kg} \mathrm{ha}^{-1}$ (Freitas et al., 2009a) e $1.208 \mathrm{~kg} \mathrm{ha}^{-1}$ (Silva, 2012), esta última, com a variedade BRS Guariba. Enquanto que as reduções de produtividade devido à interferência das plantas daninhas foram de $53,9 \%$ para a variedade BRS Xiquexique e de $55,4 \%$ para a variedade BRS Guariba, com índices inferiores aos observados por Freitas et al. (2009a), com redução de até $90 \%$. Segundo Silva et al. (2005) e Nascimento et al. (2012), o grau de interferência das plantas daninhas nas culturas pode variar em função da comunidade infestante e do ambiente, envolvendo condições climáticas, solo e manejo da cultura. 
Tabela 6. Massa de cem grãos (g) e produtividade de grãos $\left(\mathrm{kg} \mathrm{ha}^{-1}\right)$ de duas variedades de feijãocaupi submetidas a diferentes tratamentos visando ao controle de plantas daninhas. Mossoró (RN), 2010.

\begin{tabular}{|c|c|c|c|c|}
\hline \multirow{2}{*}{ Tratamentos } & \multicolumn{2}{|c|}{ Massa de cem grãos } & \multicolumn{2}{|c|}{ Produtividade } \\
\hline & BRS Xiquexique & BRS Guariba & BRS Xiquexique & BRS Guariba \\
\hline S-metholachor ${ }^{1}$ & $18,9 \mathrm{aB}$ & $22,7 \mathrm{aA}$ & $686,1 \mathrm{cA}$ & $756,7 \mathrm{cdeA}$ \\
\hline Metribuzin $^{1}$ & $0,0 \mathrm{bA}$ & $0,0 \mathrm{bA}$ & $0,0 \mathrm{dA}$ & $0,0 \mathrm{fA}$ \\
\hline Imazamox $^{2}+$ fluazifop $^{3}$ & $18,9 \mathrm{aB}$ & 22,9 aA & 910,8 abcA & 808,6 cdeA \\
\hline Bentazon $^{2}+$ fluazifop $^{3}$ & $18,1 \mathrm{aB}$ & $21,7 \mathrm{aA}$ & $723,5 \mathrm{bcA}$ & 877,7 abcA \\
\hline Imazamox + bentazon + fluazifop ${ }^{3}$ & $18,4 \mathrm{aB}$ & $21,9 \mathrm{aA}$ & $1.028,3$ abcA & $1.001,1 \mathrm{abcA}$ \\
\hline Imazethapyr $^{2}+$ fluazifop $^{3}$ & $19,5 \mathrm{aB}$ & $21,2 \mathrm{aA}$ & $1.104,2 \mathrm{abA}$ & $1.201,2 \mathrm{abA}$ \\
\hline Fomesafen $^{2}+$ fluazifop $^{3}$ & $18,4 \mathrm{aB}$ & 21,1 aA & $688,5 \mathrm{cA}$ & $532,1 \mathrm{eA}$ \\
\hline Lactofen $^{2}+$ fluazifop $^{3}$ & $19,1 \mathrm{aB}$ & $22,3 \mathrm{aA}$ & $707,8 \mathrm{cA}$ & 632,8 bcdA \\
\hline Chlorimuron $^{2}+$ fluazifop $^{3}$ & $0,0 \mathrm{bA}$ & $0,0 \mathrm{bA}$ & $0,0 \mathrm{dA}$ & $0,0 \mathrm{fA}$ \\
\hline Chlorimuron $^{2}+$ lactofen + fluazifop ${ }^{3}$ & $0,0 \mathrm{bA}$ & $0,0 \mathrm{bA}$ & $0,0 \mathrm{dA}$ & $0,0 \mathrm{fA}$ \\
\hline Capina + fluazifop ${ }^{3}$ & $18,2 \mathrm{aB}$ & 22,6 aA & $1.245,5 \mathrm{aA}$ & $1284,2 \mathrm{aA}$ \\
\hline Testemunha capinada & $19,7 \mathrm{aB}$ & $21,5 \mathrm{aA}$ & $1.213,5 \mathrm{aA}$ & $1.186,3 \mathrm{abA}$ \\
\hline Testemunha sem capina & $18,0 \mathrm{aB}$ & 21,8 aA & $777,4 \mathrm{bcA}$ & $529,2 \mathrm{eA}$ \\
\hline
\end{tabular}

\section{Conclusões}

Não há diferença de seletividade dos herbicidas entre os cultivares BRS Guariba e BRS Xiquexique. Os herbicidas bentazon + fluazifop, imazamox + fluazifop, imazamox + bentazon + fluazifop, imazetapyr + fluazifop e S-metholochlor são seletivos para a cultura do feijão caupi.

Fomesafen + fluazifop e lactofen + fluazifop causaram severa intoxicação, prolongando $\mathrm{o}$ ciclo e a redução na produtividade do feijão-caupi. Os herbicidas metribuzin, chlorimuron + fluazifop, chlorimuron + lactofen + fluazifop não seletivos para o feijão-caupi.

As misturas dos herbicidas imazamox + bentazon + fluazifop e imazetapyr + fluazifop foram eficazes no controle das espécies de plantas daninhas presentes na área. A eficácia de herbicidas varia de acordo com a comunidade infestante.

\section{Referências}

Andrade Júnior, A.S. Cultivo de feijão-caupi solos e adubação. Disponível em < http:// http://sistemasdeproducao.cnptia.embrapa.br/F ontesHTML/Feijao/FeijaoCaupi/solosadubacao .htm>>. Acesso em: 20 jun.2013.
Andrade, F.N. Avaliação e seleção de linhagens de tegumento e cotilédone verdes para o mercado de feijão-caupi verde. 2010. 110 f. Dissertação (Mestrado em Produção Vegetal) - Universidade Federal do Piauí, Teresina, 2010.

Burke, I.C.; Thomas, W.E.; Burton, J.D.; Spears, J.F.; Wilcut, J.W. A seedling assay to screen aryloxyphenoxypropionic acid and cyclohexanedione resistance in johnsongrass (Sorghum halepense). Weed Technology, v.20, n.4, p.950-955, 2006.

Corrêa, M.J.P., Alves, P.L.C.A. Eficácia de herbicidas aplicados em pós-emergência na cultura da soja convencional e transgênica. Planta Daninha, v.27, n.esp., p.1035-1046, 2009.

Fontes, J.R.A.; Gonçalves, J.R.P.; Morais, R.R. Tolerância do feijão-caupi ao herbicida oxadiazon. Pesquisa Agropecuária Tropical, v.40, n.1, p.110-115, 2010.

Freire Filho, F.R. Feijão-caupi no Brasil: produção, melhoramento genético, avanços e desafios. Teresina, PI: Embrapa Meio-Norte, 2011. 84p.

Freitas, F.C.L.; Medeiros, V.F.L.P.; Grangeiro, L.C.; Silva, M.G.O.; Nascimento, P.G.M.L.; 
Nunes, G.H. Interferência de plantas daninhas na cultura do feijão-caupi. Planta Daninha, v.27, n.2, p.241-247, 2009a.

Freitas, F.C.L.; Dallabona, J.D.; Mesquita, H.C.; Fontes, L.O. Manejo de plantas daninhas na cultura do feijão-caupi. In: II Congresso Nacional de Feijão-caupi. Palestras... [CD ROM] Belém, 2009b.

Freitas, F.C.L.; Mesquita, H.C.; Freitas, M.A.M.; Felipe, R.S.; Guimarães, F.C.N. Seletividade de herbicidas para a cultura do feijão-caupi. In: Congresso Brasileiro da Ciência das Plantas Daninhas, 27, 2010. Ribeirão Preto, Anais ... Ribeirão Preto: SBCPD, 2010. p. 1248-1742.

Galon, L.; Pinto, J.J.O.; Agostinetto, D.; Magro, T.D. Controle de plantas daninhas e seletividade de herbicidas à cultura da soja, aplicados em dois volumes de calda. Revista Brasileira Agrociência, v.13, n.3, p.325-330, 2007.

Harrison Jr., H.F.; Fery, R.L. Differential bentazon response in cowpea (Vigna unguiculata). Weed Technology, v.10, n.3, p.756-758, 1993.

Linhares, C.M.S.; Freitas, F.C.L.; Silva, K.S.; Lima, M.F.P.; Dombroski, J.L.D. Crescimento do feijão-caupi sob efeito dos herbicidas fomesafen e bentazon + imazamox. Revista Caatinga, v.27, n.1, p.41-49, 2014

Machado, A.F.L.; Camargo, A.P.M.; Ferreira, L.R.; Sediyama, T.; Fereira, F.A.; Viana, R.G. Misturas de herbicidas no manejo de plantas daninhas na cultura do feijão. Planta Daninha, v.24, n.1, p.107-114, 2006.

Marques, L.J.P.; Silva, M.R.M.; Lopes, G.S.; Corrêa, M.J.P.; Araújo, M.S.; Costa, E.A. et al. Dinâmica de populações e fitossociologia de plantas daninhas no cultivo do feijão-caupi e mandioca no sistema corte e queima com o uso de arado. Planta Daninha, v.29, n.esp., p.981989, 2011.

Nascimento, P.G.M.L.; Silva, M.G.O.; Fontes, L.O.; Rodrigues, A.P.M.; Medeiros, M.A.;
Freitas, F.C.L. Levantamento fitossociológico das comunidades infestantes em diferentes sistemas de plantio de milho. Agropecuária Científica no Semi-Árido, v.7, n.3, p.1-9, 2011.

Rocha, M.M.; Freire Filho, F.R.; Ribeiro, V.Q.; Carvalho, H.W.L.; Belarmino Filho, J. et al. Adaptabilidade e estabilidade produtiva de genótipos de feijão-caupi de porte semi-ereto na região Nordeste do Brasil. Pesquisa Agropecuária Brasileira, v.42, n.9, p.12831289, 2007.

Silva, A.A.; Silva, C.S.W.; Souza, B.A.; Fagundes, J.L.; Falleiro, R.M.; Sediyama, C.S. Aspectos fitossociológicos da comunidade de plantas daninhas na cultura do feijão sob diferentes sistemas de preparo do solo. Planta Daninha, v.23, n.1, p.17-24, 2005.

Silva, D. V.; Santos, J. B.; Silveira, H. M.; Carvalho, F.P.; Castro Neto, M.D.; Silva, A.A.; Cecon, P.R. Tolerância de cultivares de mandioca aos herbicidas fomesafen e fluazifopp-butil. Revista Brasileira de Herbicidas, v.10, n.3, p.219-231, 2011.

Silva, E.B.; Barros Júnior, A.P.; Silveira, L.M.; Santana, F.M.S.; Santos, M.G. Avaliação de cultivares de feijão-caupi irrigado para produção de grãos verdes em Serra Talhada PE. Revista Caatinga, v.26, n.1, p.21-26, 2013.

Silva, J.B.F.; Pitombeira, J.B.; Nunes, R.P.; Pinho, J.L.N.; Cavalcante Júnior, A.T. Controle de plantas daninhas em feijão-de-corda em sistema de semeadura direta. Planta Daninha, v.21, n.1, p.151-157, 2003.

Silva, J.F.; Albertino, S.M.F. Manejo de plantas daninhas. In: Zilli, J.E.; Vilarinho, A.A.; Alves, J.M.A. A cultura do feijão-caupí na Amazônia brasileira. Boa Vista-RR: Embrapa Roraima, 2009. p. 223-243.

Silva, K.S. Eficiência de herbicidas para a cultura do feijão-caupi. 2012. 40p. Dissertação (Mestrado em Fitotecnia) - Universidade Federal Rural do Semi-Árido (UFERSA), Mossoró. 